\title{
Dose-dependent effects induced by cadmium in polychaete Perinereis aibuhitensis
}

\author{
Feng Liu ${ }^{\mathrm{a}}$, Zhen $\mathrm{Lu}^{\mathrm{b}, \mathrm{c}}$, Huifeng $\mathrm{Wu}^{\mathrm{b}, \mathrm{c}}$, Chenglong $\mathrm{Ji}^{\mathrm{b}, \mathrm{c}, *}$ \\ ${ }^{a}$ Ocean College, Yantai Research Institute of China Agricultural University, Yantai 264670, PR China \\ ${ }^{\mathrm{b}}$ Laboratory for Marine Fisheries Science and Food Production Processes, Qingdao National Laboratory for Marine Science and Technology, Qingdao 266237, PR China \\ ${ }^{c}$ Key Laboratory of Coastal Environmental Processes and Ecological Remediation, Yantai Institute of Coastal Zone Research (YIC), Chinese Academy of Sciences (CAS); \\ Shandong Provincial Key Laboratory of Coastal Environmental Processes, YICCAS, Yantai 264003, PR China
}

A R T I C L E IN F O

\section{Keywords:}

Cadmium

Dose-dependent

Toxicological effects

Hormesis

Perinereis aibuhitensis

\begin{abstract}
A B S T R A C T
Cadmium is a known metal contaminant in the Bohai Sea. In this study, the dose-dependent responses induced by Cd were characterized in marine polychaete Perinereis aibuhitensis using the endpoints, including activities of enzymes, expression levels of stress-responsive genes and metabolic responses. Both enzyme activities and gene expression levels exhibited the hormetic effects induced by $\mathrm{Cd}$ in $P$. aibuhitensis, as shown by the typical Ushaped or inverted U-shaped response profiles. The highest concentration $(1280 \mu \mathrm{g} / \mathrm{L})$ of Cd exposure induced obvious oxidative stresses. NMR-based metabolomics revealed that Cd induced both linear dose-dependent effects $(69.13 \%$ of the total variation) and a relatively slight hormesis (5.54\% of the total variation) in energy metabolism in P. aibuhitensis at metabolite level. In details, Cd exposures linearly reduced the consumption of amino acids and enhanced the consumption of glucose for energy supply, resulting in elevated contents of amino acids and depleted contents of glucose. Additionally, Cd treatments induced hormesis in the conversion of ATP hydrolysis to AMP. This work suggested that the hormetic effects should be considered in the ecological risk assessment for the environmental pollutants.
\end{abstract}

\section{Introduction}

Cadmium (Cd) is an important industrial material. It is also an impurity with some minerals, such as zinc (Zn). Therefore, Cd can easily enter into the environment. As a nonessential metal element, Cd can be strongly bio-accumulated and its excessive level can induce diverse toxicities in organisms (Bertin and Averbeck, 2006; De Silva et al., 2018; Pavlakia et al., 2017). Along the Bohai coast, there are numerous metal smelteries with unavoidable pollution discharges containing Cd. Many surveys have reported the Cd pollution in the Bohai Sea (Gao et al., 2014; Ji et al., 2016). Our studies have also found that Cd is one of the most frequently detectable metal contaminants in marine organisms sampled from the Bohai Sea (Ji et al., 2016; Xu et al., 2016). In 2016, the significant Cd accumulations were detected in shrimps Crangon affinis sampled from several sites along the Laizhou Bay in the Bohai Sea (Xu et al., 2016). In the gastropods and oysters collected in 2002 along the coastline of the Bohai Sea, the concentration of Cd significantly exceeded the maximum permissible level (MPL) for Cd in food product recommended by the World Health Organization (WHO)
(Liang et al., 2004). The seawater concentration of Cd reached $5 \mu \mathrm{g} / \mathrm{L}$ that was detected in the seawater from the Jinzhou Bay in the Bohai Sea from 1987 to 1990 (Ma et al., 1995). The maximum seawater concentration of Cd was approximately $16 \mu \mathrm{g} / \mathrm{L}$ detected in the seawater from the Liaodong Bay in the Bohai Sea in 2000 (Zhang, 2001). These evidence confirmed the historic contamination of $\mathrm{Cd}$ in the Bohai Sea, which may pose threats on the marine organisms and human body via food chain transfer. Therefore, it is necessary to investigate the toxicological effects of $\mathrm{Cd}$ in marine organisms.

Usually, the environmental concentration of $\mathrm{Cd}$ in seawater is as low as the level of $\mu \mathrm{g} / \mathrm{L}$. In toxicology, however, there is an interesting dose-response relationship named hormesis when the toxicant concentration is very low (Chapman, 2002). The hormesis is generally characterized by the low-dose stimulation and high-dose inhibition phenomenon that significantly influences the ecological risk assessment for environmental pollutants. Based on its definition, the hormesis refers to a biphasic but a linear dose response to the toxicants (Calabrese and Baldwin, 2000). The hormetic effect was hypothesized to be the overcompensation to a perturbation in homeostasis (Stebbing, 1998,

\footnotetext{
* Corresponding author at: Key Laboratoty of Coastal Environmental Process and Ecological Remediation, Yantai Institute of Coastal Zone Research, Chinese Academy of Sciences (CAS), Yantai 264670, PR China

E-mail address: clji@yic.ac.cn (C. Ji).
} 
2000). In other words, organisms can not only repair the damage, but also more effectively overcompensate and reduce background damage induced by stressors, such as pollutants. This hormetic effect can be characterized by either a U-shaped or an inverted U-shaped dose response profile, depending on the endpoints measured (Calabrese and Baldwin, 2003). In ecotoxicology, the hormetic effects of Cd have been frequently observed. Zhang et al. (2009) found that the low concentrations of Cd increased the activities of catalase (CAT) and superoxide dismutase (SOD), but high concentrations of Cd inhibited the activities of these enzymes in an inverted U-shaped curve in earthworm Eisenia fetida. In another study, Nascarella et al. (2003) observed that low levels of cadmium significantly enhanced the pupation rate, while higher doses inhibited pupation rate of larval queen blowfly Phormia regina, resulting in an inverted $\mathrm{U}$-shaped response profile. In marine ecotoxicology, however, there are few reports related to Cd-induced dose-dependent responses in marine organisms.

The marine polychaete Perinereis aibuhitensis is a key species of the benthic community in coastal sediments. Since this sediment-dwelling ragworm is sensitive to marine pollutants, including metals $(\mathrm{Pb}, \mathrm{Hg}$, etc.) and organic compounds (petroleum hydrocarbons), it has been increasingly used as a bioindicator in marine ecotoxicology recently (Tian et al., 2014; Zhang et al., 2017). In this work, the marine polychaete $P$. aibuhitensis was used to test the dose-dependent responses of $\mathrm{Cd}$. The endpoints, including activities of enzymes, expression levels of stress-responsive genes and metabolite profiles, were characterized to elucidate the dose-dependent responses of $\mathrm{Cd}$ in the marine polychaete P. aibuhitensis.

\section{Materials and methods}

\subsection{Experimental animals and conditions}

One hundred and twenty adult individuals of $P$. aibuhitensis (weight: $1.9 \pm 0.3 \mathrm{~g}$ ) were collected from a culturing farm in Dongying, China. After transported to the culture laboratory, the animals were allowed to acclimate in aerated seawater $\left(20 \pm 0.5^{\circ} \mathrm{C}, 32.5 \mathrm{psu}\right.$, collected from a pristine environment) in the laboratory for 1 week. After acclimation, the individuals of $P$. aibuhitensis were randomly divided into six groups (one control and five Cd exposures, respectively). Each group contained two replicate beakers each containing ten individuals of $P$. aibuhitensis in $3 \mathrm{~L}$ of aerated seawater. Five sublethal concentrations (5, 20, 80, 320 and $1280 \mu \mathrm{g} / \mathrm{L}$ ) of Cd were used for the dose-dependent exposures for $P$. aibuhitensis. The highest concentration $(1280 \mu \mathrm{g} / \mathrm{L})$ of $\mathrm{Cd}$ was approximately $10 \%$ of the LC50 $(\sim 12,000 \mu \mathrm{g} / \mathrm{L}$, unpublished value in our laboratory) for $P$. aibuhitensi at $96 \mathrm{~h}$. After exposure for $96 \mathrm{~h}, 10 \mathrm{in}$ dividuals of $P$. aibuhitensis were randomly sampled from each group. During acclimation and exposure periods, these animals were fasted and no mortality was found. Each sample was snap-frozen in liquid nitrogen and ground into a homogeneous mixture under liquid nitrogen. Then the ground mixture was divided into four parts for metabolite extraction, RNA extraction, enzyme activity measurement and $\mathrm{Cd}$ determination. These samples were stored at $-80^{\circ} \mathrm{C}$ before further procedures.

\subsection{Metabolite extraction}

Polar metabolites in the whole soft tissues of $P$. aibuhitensis $(n=10$ for each treatment) were extracted by the modified metabolite extraction protocol as described previously (Zhang et al., 2011). Briefly, the soft tissue (ca. $100 \mathrm{mg}$ wet weight) was homogenized and extracted using a solvent combination of $4 \mathrm{~mL} / \mathrm{g}$ of methanol, $5.25 \mathrm{~mL} / \mathrm{g}$ of water and $2 \mathrm{~mL} / \mathrm{g}$ of chloroform. The polar layer (methanol/water) with metabolites was transferred to a glass vial and dried in a centrifugal concentrator. The extracts were then dissolved in $600 \mu \mathrm{L}$ of phosphate buffer $\left(100 \mathrm{mM} \mathrm{Na}_{2} \mathrm{HPO}_{4}\right.$ and $\mathrm{NaH}_{2} \mathrm{PO}_{4}$, containing $0.5 \mathrm{mM}$ TSP as the internal standard, $\mathrm{pH}$ 7.0) in $\mathrm{D}_{2} \mathrm{O}$. The mixture was vortexed and centrifuged at $3000 \mathrm{~g}$ for $5 \mathrm{~min}$ at $4{ }^{\circ} \mathrm{C}$. A volume of $550 \mu \mathrm{L}$ of the supernatant substance was pipetted into a $5 \mathrm{~mm}$ NMR tube for NMR analysis.

\section{3. ${ }^{1} H$ NMR spectroscopy}

Metabolite extracts of $P$. aibuhitensis were analyzed on a Bruker AV 500 NMR spectrometer at $25^{\circ} \mathrm{C}$ as described previously (Zhang et al., 2011). All ${ }^{1} \mathrm{H}$ NMR spectra were manually phased, baseline-corrected, and calibrated (TSP at $0.0 \mathrm{ppm}$ ) using TopSpin (version 2.1, Bruker).

\subsection{Spectral pre-processing and data analysis}

All one dimensional ${ }^{1} \mathrm{H}$ NMR spectra were converted to a data matrix using the ProMetab software in Matlab version 7.0 (The MathsWorks, Natick, MA) (Viant et al., 2009). Each spectrum was segmented into bins with a width of $0.005 \mathrm{ppm}$ between 0.2 and $10.0 \mathrm{ppm}$. The bins of residual water peak between 4.70 and $5.20 \mathrm{ppm}$ were removed from the NMR spectral data matrix. The total spectral area of the remaining bins was normalized to unity to facilitate the comparison between the spectra. Principal components analysis (PCA) was performed to detect the dose-dependent response profiles related to Cd exposures using PLS Toolbox (version 4.0, Eigenvector Research, Manson, WA) (Zhang et al., 2011). Metabolites were identified and quantified by using the software, Chenomx (Evaluation Version, Chenomx Inc., Edmonton, Alberta, Canada) (Viant et al., 2009). The metabolite concentrations $(\mathrm{mM})$ were determined by the concentration $(0.5 \mathrm{mM})$ of internal standard, TSP.

\subsection{Enzyme activities}

The enzyme activities in $P$. aibuhitensis $(n=10)$ were measured using a multimode microplate reader (Infinite M200, TECAN, Switzerland) according to the manufacturer's protocols for enzyme kits (Jiancheng, Nanjing, China). In this work, the enzymes for the activity measurement included superoxide dismutase (SOD, EC 1.15.1.1), glutathione S-transferases (GST, EC 2.5.1.18), catalase (CAT, EC 1.11.1.6) and acetylcholinesterase (AChE, EC 3.1.1.7). Protein concentration was determined using the Coomassie brilliant blue G-250 dye-binding method with bovine serum albumin as standard (Bradford, 1976). The unit of enzymes was defined as the activity of an enzyme per milligram of total protein ( $\mathrm{U} / \mathrm{mg}$ protein).

\subsection{RNA extraction and quantitation of gene expressions}

Total RNA from the soft tissue samples of $P$. aibuhitensis $(n=10)$ was extracted following the manufacturer's directions (Invitrogen), and the first strand cDNA was synthesized according to M-MLV RT Usage information (Promega). For gene expression analysis, eight stress-responsive genes were selected and the corresponding primers were listed in Table 1. These genes for expression quantification included SOD, CAT, heat shock protein 70 (HSP 70), heat shock protein 90 (HSP 90), cytochrome P450 (CYP450), cytochrome oxidase subunit I (COI), metalloprotein $(M P)$ and vitellogenin $(V T G)$. The beta-actin gene ( $\beta$-actin) was chosen as the reference gene and its primers were also listed in Table 1.

The fluorescent real-time quantitative PCR amplifications were conducted in triplicate in a total volume of $20 \mu \mathrm{L}$, containing $10 \mu \mathrm{L}$ of $2 \times$ SYBR Premix Ex Taq ${ }^{\text {TM }}$ (TaKaRa), $0.4 \mu \mathrm{L}$ of $50 \times$ ROX Reference DYE II, $4.8 \mu \mathrm{L}$ of DEPC-treated $\mathrm{H}_{2} \mathrm{O}, 0.4 \mu \mathrm{L}$ of each primer and $4.0 \mu \mathrm{L}$ of $1: 20$ diluted cDNA. The PCR program was as following: $50{ }^{\circ} \mathrm{C}$ for $2 \mathrm{~min}$ and $95^{\circ} \mathrm{C}$ for $10 \mathrm{~min}$, followed by 40 cycles of $94^{\circ} \mathrm{C}$ for $15 \mathrm{~s}, 58^{\circ} \mathrm{C}$ for $45 \mathrm{~s}$, $72^{\circ} \mathrm{C}$ for $30 \mathrm{~s}$. Dissociation curve analysis of amplification products was performed at the end of each PCR to confirm that only one PCR product was amplified and detected. After the PCR program, data were analyzed with the ABI 7500 SDS software (Applied Biosystems). To maintain 
Table 1

The list of primers used for the determination of internal control and quantification of gene expressions by qPCR.

\begin{tabular}{|c|c|c|c|}
\hline Gene name & Accession No. & Forward primer $\left(5^{\prime}-3^{\prime}\right)$ & Reverse primer $\left(5^{\prime}-3^{\prime}\right)$ \\
\hline$\beta$-actin & JN609588 & GGGCTACTCCTTCACCACCA & CGAAGTCCAGAGCAACATAGCA \\
\hline$S O D$ & KF199864 & TGCTGATGTAGATGACCTTG & CTATTGAGTGATTCCGATGAC \\
\hline$C A T$ & KF199863 & GCCCAGCCCACTTCATTC & СTCCСTCTTGGTTATCAGACAC \\
\hline HSP 70 & HQ449186 & ACGCTACACACGAGAAAACACAA & GAAAACCCCAACGCAGGA \\
\hline HSP 90 & KU535887 & CTACTCAGCCTATCTTGTG & CCTTGATTCTCTTCTCTTCC \\
\hline CYP 450 & HM126463 & ACACCACAGCATCAGGAATATC & CGCCAGCAACTCGTCAAG \\
\hline $\mathrm{COI}$ & GU362686 & CGACAGTCATCAACATACGCTCAA & TCCTCCCGCAGGGTCAAAG \\
\hline$M P$ & FJ212325 & CGTCAACCACATCAAGGGAAC & CCCGCTGAAACGACACTAACA \\
\hline$V T G$ & KF212194 & CCGAGAAGGTTGGAGATGTG & GGAGGATGTAGTCAGCAATGG \\
\hline
\end{tabular}

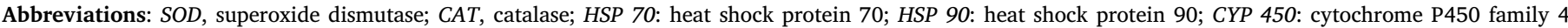
protein; COI: cytochrome oxidase subunit I; MP: metalloprotein; VTG: vitellogenin.

consistency, the baseline was set automatically by the software. The comparative CT method ( $2^{-\Delta \Delta \mathrm{CT}}$ method) was employed to analyze the expression levels of these genes (Livak and Schmittgen, 2001).

\subsection{Cd determination}

The soft tissue samples $(n=10)$ of $P$. aibuhitensis were dried at $80^{\circ} \mathrm{C}$ to constant weights. The dried tissues were digested in concentrated $\mathrm{HNO}_{3}(70 \%$, Fisher Scientific) in a microwave digestion system (CEM, MAR5). The samples were heated in a microwave oven (heating to $200{ }^{\circ} \mathrm{C}$ and holding at $200^{\circ} \mathrm{C}$ for $15 \mathrm{~min}$ ). All digested samples were diluted with ultrapure water for Cd determination using ICP-MS technique (Agilent 7500i, Agilent Technologies Co. Ltd., Santa Clara, CA, USA). GBW08571 Marine mussel tissue was used as a certified reference for Cd determination to ensure internal quality assurance/quality control (QA/QC) practices (Li et al., 2012). The recovery was restricted within $95.5-104.3 \%$ for $\mathrm{Cd}$.

\subsection{Statistical analysis}

The biochemical indices, including Cd concentrations, enzyme activities, metabolites and gene expressions in the samples of $P$. aibuhitensis, were expressed as means \pm standard deviation and tested for normal distribution (Ryan-Joiner's test) and homogeneity of variances (Bartlett's test). One way analysis of variance (ANOVA) with Tukey's test was conducted on the biochemical indices from control and $\mathrm{Cd}$ treatments, respectively. The $P$ values less than 0.05 were considered statistically significant. The Minitab software (Version 15, Minitab Inc., USA) was used for the statistical analysis.

\section{Results and discussion}

\subsection{Cd accumulation in $P$. aibuhitensis}

Cd can be easily bio-accumulated and induce toxic effects in organisms (Bertin and Averbeck, 2006; Gu et al., 2018). Although the average tissue $\mathrm{Cd}$ concentration was higher in the lowest concentration $(5 \mu \mathrm{g} / \mathrm{L})$ of Cd-exposed group than that in control group after Cd exposure for $96 \mathrm{~h}$, there was no significance between these two groups because of the short exposure time (Fig. 1). For other four Cd-treated groups, the $P$. aibuhitensis accumulated significant $(P<0.05$ or 0.01$)$ amounts of $\mathrm{Cd}$ in the soft tissues. Apparently, the accumulated $\mathrm{Cd}$ contents in Cd treatments were significantly $(P<0.05)$ increased with the gradually increased $\mathrm{Cd}$ concentrations for exposures (Fig. 1). Especially, Cd accumulations in the two highest concentrations (320 and $1280 \mu \mathrm{g} / \mathrm{L}$ ) of Cd treatments were approximately 20 and 60 times higher than that in controls, respectively. The significant accumulations of Cd might induce detectable toxicological effects in $P$. aibuhitensis.

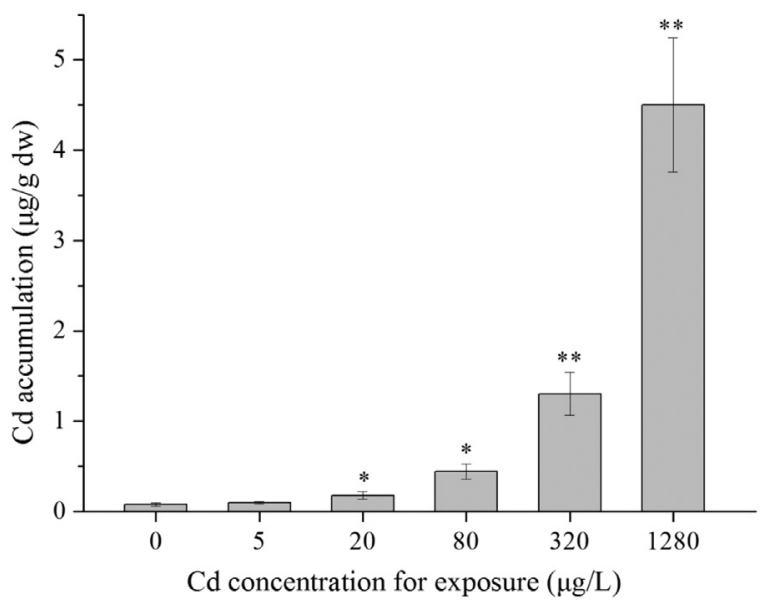

Fig. 1. The accumulated Cd concentrations ( $\mu \mathrm{g} / \mathrm{g}$ dry weight) in polychaete $P$. aibuhitensis after Cd exposures for $96 \mathrm{~h}$. Cd concentrations are presented as the mean \pm standard deviation. Statistical significances $(P<0.05, *$ and $P<0.01, * *)$ between control and Cd treatments were determined by one way ANOVA.

\subsection{Dose-dependent effects of $C d$ on the enzyme activities in P. aibuhitensis}

To explore the dose-dependent effects of Cd in P. aibuhitensis, several biochemical endpoints, including enzyme activities, gene expression levels and metabolites, were tested. As shown in Fig. 2, the responses of SOD activities in $P$. aibuhitensis presented an inverted Ushaped curve, while the responses of CAT activities interestingly revealed a typical U-shaped curve. This finding clearly demonstrated the hormetic effects of $\mathrm{Cd}$ in $P$. aibuhitensis. Zhang et al. also observed the hormetic effects of Cd in earthworm Eisenia fetida, using SOD and CAT activities as the endpoints (Zhang et al., 2009). At cellular level, the exogenous toxicants often induce oxidative stress in organisms, resulting from the excessive production of reactive oxygen species (ROS). SOD is an enzyme that catalyzes the dismutation of the superoxide $\left(\mathrm{O}_{2}{ }^{-}\right)$radical into either ordinary molecular oxygen $\left(\mathrm{O}_{2}\right)$ or hydrogen peroxide $\left(\mathrm{H}_{2} \mathrm{O}_{2}\right)$. CAT can catalyze the decomposition of hydrogen peroxide to water and oxygen. These two enzymes are very important enzymes in protecting the cell from oxidative damage by ROS. Cd is a known toxicant that induces oxidative stress in organisms (Bertin and Averbeck, 2006). In this work, the elevated SOD activities confirmed that $\mathrm{Cd}$ produced excessive superoxide radicals in $P$. aibuhitensis. In the highest concentration $(1280 \mu \mathrm{g} / \mathrm{L})$ of Cd treatment, the SOD activity somewhat recovered (Fig. 2). However, the CAT activity was highly significantly $(P<0.01)$ increased. It seemed that the highest concentration $(1280 \mu \mathrm{g} / \mathrm{L})$ of Cd induced more hydrogen peroxide but superoxide in $P$. aibuhitensis. GST, as the phase II metabolic isozyme, is known to catalyze the conjugation of the reduced form of glutathione (GSH) to xenobiotic substrates for the purpose of detoxification. AChE 

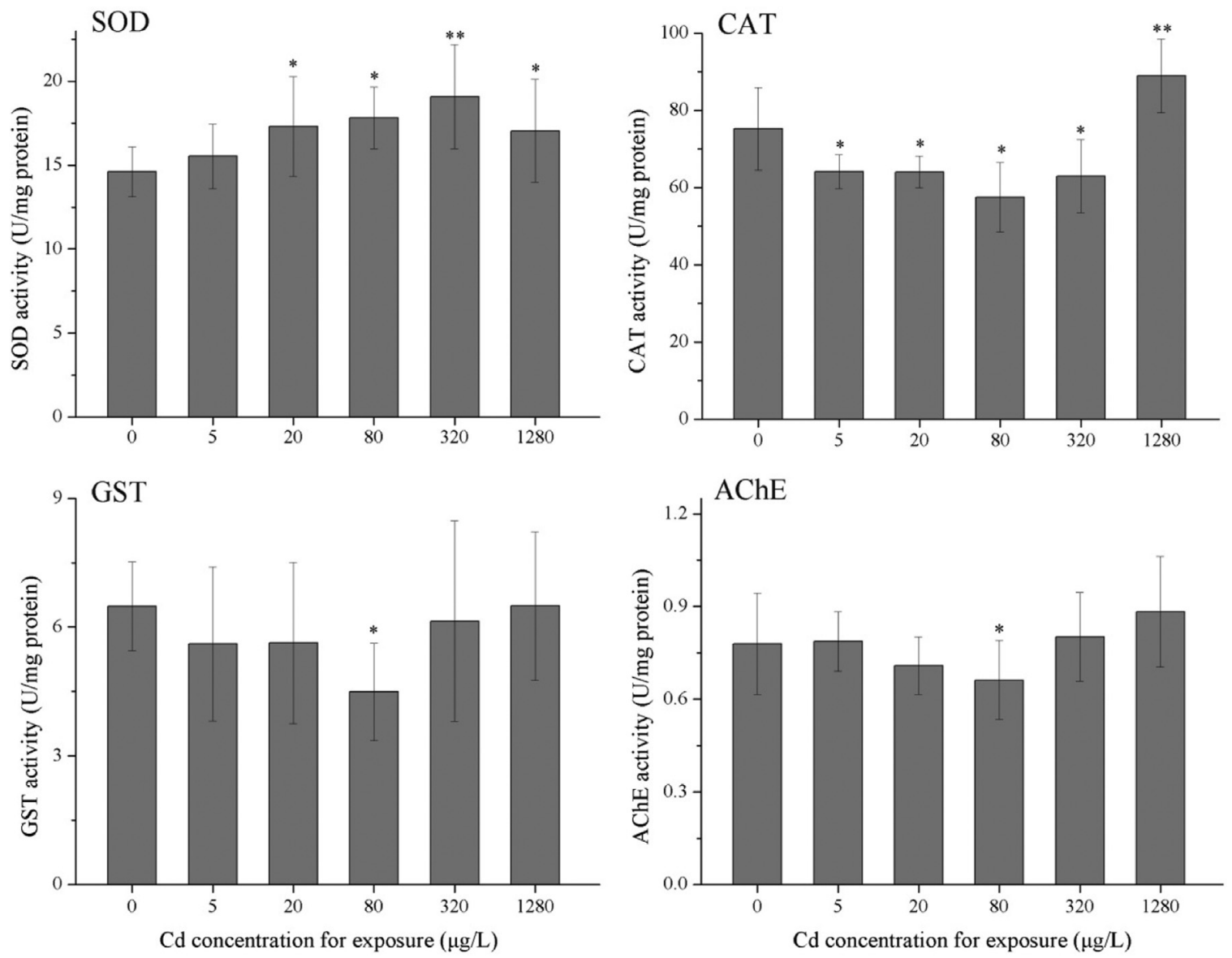

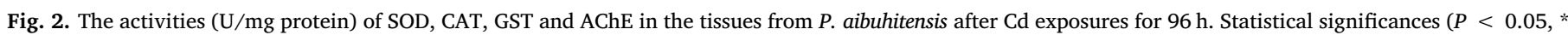

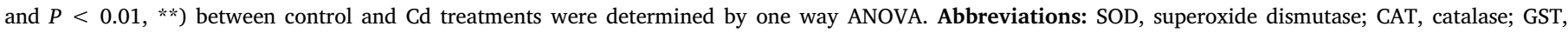
glutathione S-transferases; AChE, acetylcholinesterase.

catalyzes the breakdown of acetylcholine and of other choline esters that function as neurotransmitters (Quinn, 1987). It is therefore a known biomarker of neurotoxicity. For both GST and AChE, their activities were only significantly inhibited by the moderate concentration $(80 \mu \mathrm{g} / \mathrm{L})$ of $\mathrm{Cd}$ in $P$. aibuhitensis. Other concentrations of Cd for exposure didn't induce significant changes in GST and AChE activities. However, their dose response profiles were displayed in U-shaped-like curves, which suggested the slight hormetic effects of $\mathrm{Cd}$ in P. aibuhitensis, using GST and AChE activities as the endpoints.

\subsection{Dose-dependent effects of Cd on the gene expression levels in $P$. aibuhitensis}

Few researches focused on the hormetic effects of Cd or other toxicants in marine ecotoxicology at mRNA level. In this work, eight typical stress-responsive genes, including SOD, CAT, HSP 70, HSP 90, CYP450, COI, MP and VTG, were selected for the quantification of mRNA expressions. Among these genes, SOD, CAT, HSP 70, HSP 90, CYP450 and COI are invariably associated with oxidative stress induced by the increased reactive oxygen species production and cellular toxicity caused by toxicants (Fridovich, 1995; Lewis et al., 1999; Srinivasan and Avadhani, 2012). The metalloprotein (MP) has a capacity to bind metals resulting in detoxification of metals, such as Cd (Yang et al., 2011). Vitellogenin (VTG) is a precursor protein of egg yolk used as a biomarker of reproductive toxicity to environmental toxicants which stimulate elevated levels of vitellogenin in organisms (Liu et al., 2016). After exposure with $\mathrm{Cd}$ for $96 \mathrm{~h}$, the expression profile of $S O D$ indicated a U-shaped curve (Fig. 3) that is interestingly opposite to that presented by SOD activities (Fig. 2). The disparity between mRNA expression of
SOD and corresponding SOD activity was not surprising, since mRNA expression means the tendency of its encoded protein. However, it does not always happen because of the posttranscriptional and posttranslational modifications and differential degradation rates between mRNA and protein (enzyme). In addition, the activities of SOD include the total activities of the SOD family. For both CAT and HSP 90, the expression profiles of their mRNAs were shown in U-shaped-like curves with or without significances for the expression levels from each $\mathrm{Cd}$ treatment (Fig. 3), which confirmed the hormetic effects induced by $\mathrm{Cd}$ in $P$. aibuhitensis at mRNA level, together with the expression profiles of $S O D$ and MP. In details, the gene expressions of SOD, CAT, HSP 90 and $M P$ were more obviously inhibited in the moderate concentration $(80 \mu \mathrm{g} / \mathrm{L})$ of Cd-treated group, while the most significant $(P<0.05)$ overexpressions of these genes (except $M P, P>0.05$ ) were observed in the highest concentration $(1280 \mu \mathrm{g} / \mathrm{L})$ of Cd-treated group. It suggested that the highest concentration of $\mathrm{Cd}$ induced clear oxidative stress and MP was mobilized to detoxify the toxicity of excessively accumulated $\mathrm{Cd}$ in $P$. aibuhitensis. The expression profile of $\mathrm{COI}$ was also seen in a Ushaped curve demonstrating the hormesis of $\mathrm{Cd}$ in $P$. aibuhitensis. However, the most significant inhibition of $\mathrm{COI}$ in $P$. aibuhitensis was caused by the second lowest concentration $(20 \mu \mathrm{g} / \mathrm{L})$ of $\mathrm{Cd}$ but the moderate concentration ( $80 \mu \mathrm{g} /)$. For HSP 70, CYP 450 and $V T G$, their mRNA expression profiles were found in neither linear responses nor hormetic curves. It might be interpreted that the hormesis for these genes could be located at other Cd concentration ranges. To achieve an overall view on the dose-dependent responses at mRNA level in P. aibuhitensis to Cd, a global analysis of gene expression (transcriptomics) is necessary in the future work. 

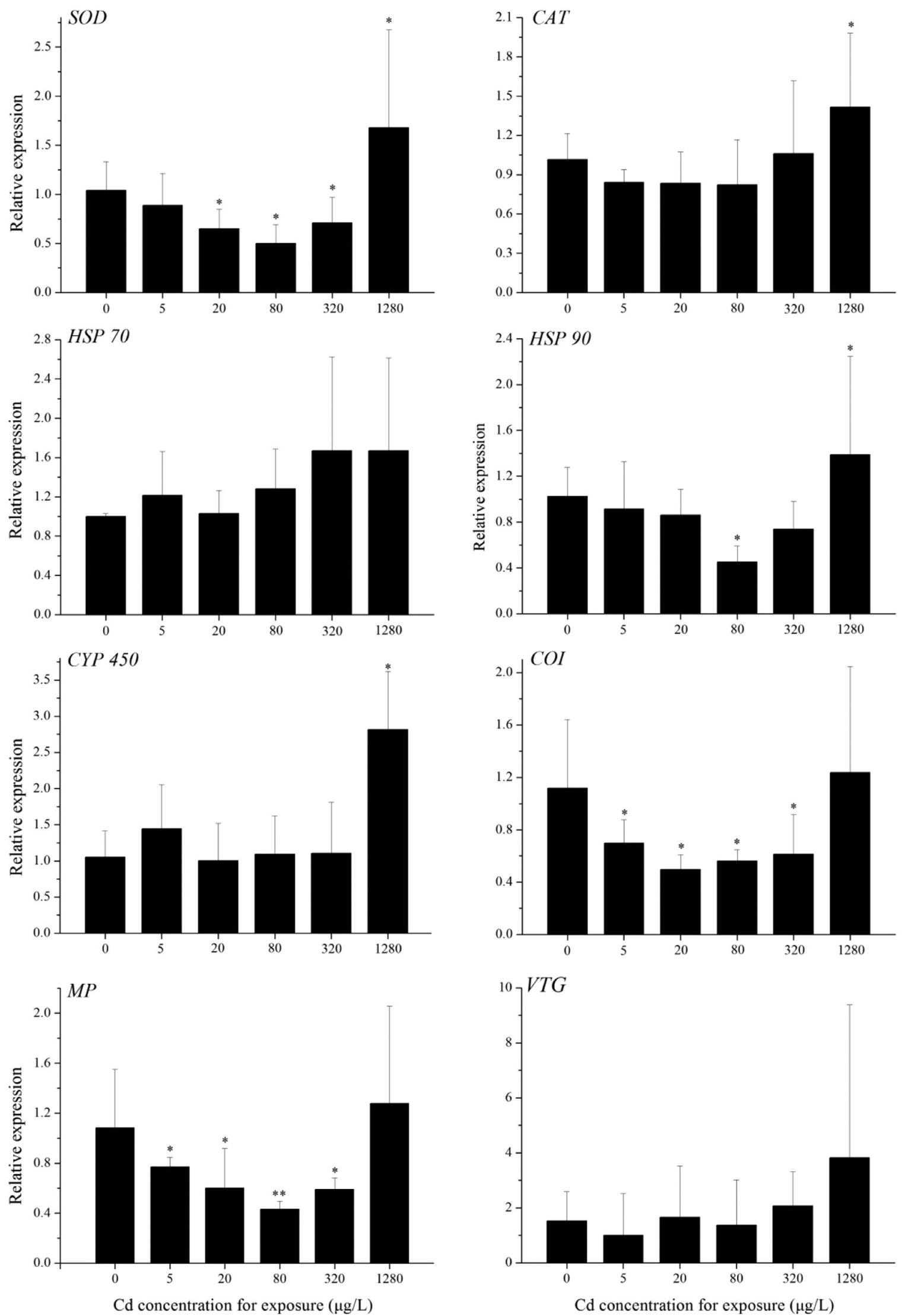

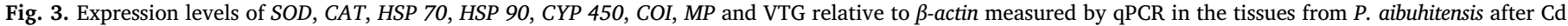

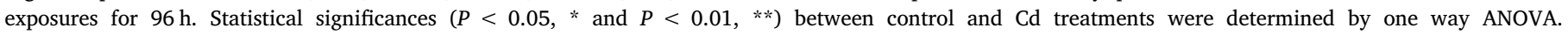

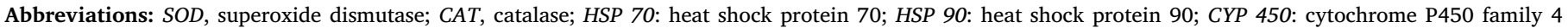
protein; COI: cytochrome oxidase subunit I; MP: metalloprotein; VTG: vitellogenin. 


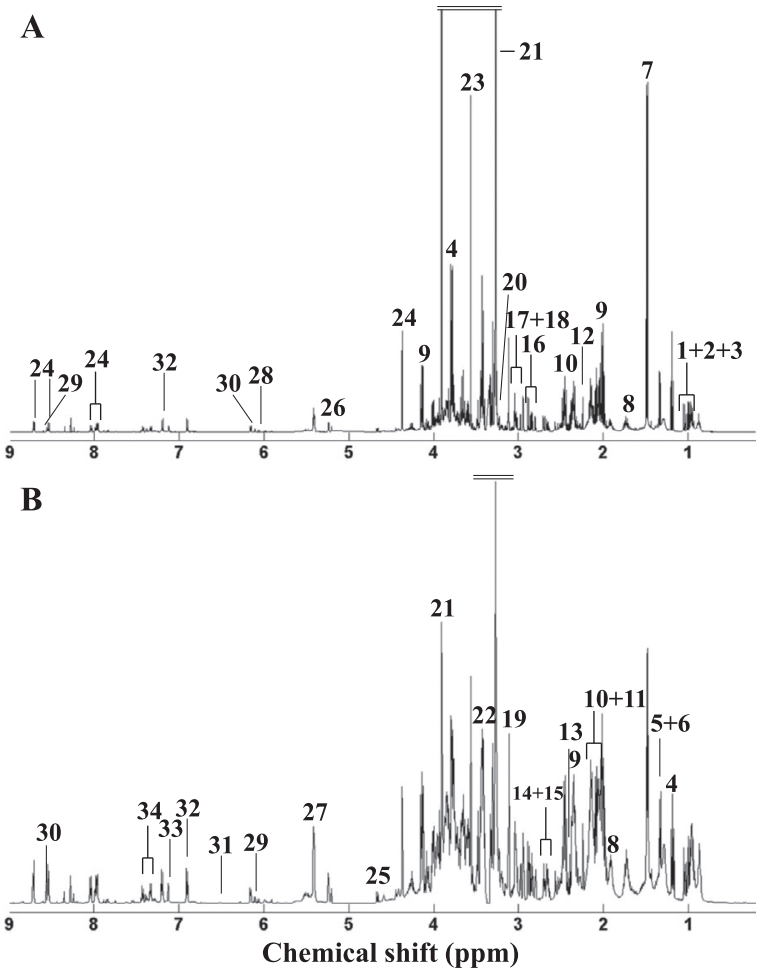

Fig. 4. A representative 1-dimensional ${ }^{1} \mathrm{HNMR}$ spectrum of metabolite extracts of $P$. aibuhitensis from control group, in original (A) and generalized logtransformed (B) forms. Keys: (1) isoleucine, (2) leucine, (3) valine, (4) ethanol, (5) lactate, (6) threonine, (7) alanine, (8) saccharopine, (9) proline, (10) glutamate, (11) glutamine, (12) acetone, (13) succinate, (14) hypotaurine, (15) aspartate, (16) asparagine, (17) creatine phosphate, (18) creatine, (19) malonate, (20) phosphocholine, (21) betaine, (22) taurine, (23) glycine, (24) homarine, (25) $\beta$-glucose, (26) $\alpha$-glucose, (27) glycogen, (28) inosine, (29) AMP, (30) ATP, (31) fumarate, (32) tyrosine, (33) histidine and (34) phenylalanine.

\subsection{Dose-dependent effects of Cd at metabolite level in P. aibuhitensis}

Metabolomics has been widely used in ecotoxicology (Viant et al., 2009). In this work, NMR-based metabolomics was applied to detect the dose-dependent effects of $\mathrm{Cd}$ in P. aibuhitensis at metabolite level. A total of 34 metabolites in the whole tissue extracts of $P$. aibuhitensis were identified and labeled in Fig. 4. These metabolites were classified into several classes, including amino acids (isoleucine, leucine, valine, alanine, glycine, etc.), intermediates in the Krebs cycle (succinate and fumarate), organic osmolytes (hypotaurine, betaine, taurine and homarine) and energy storage compounds (glucose, ATP and glycogen). Principal component analysis (PCA) was performed on the NMR spectral data from control and all concentrations of Cd-treated groups. As shown in Fig. 5A and B, the average PC scores along PC1 $(38.39 \%$ variation) and PC2 (30.74\% variation) axes were linearly decreased and increased, respectively. The two higher concentrations (320 and $1280 \mu \mathrm{g} / \mathrm{L})$ of Cd-treated groups were significantly $(P<0.05)$ separated along PC1 axis. Except the lowest concentration ( $5 \mu \mathrm{g} / \mathrm{L})$ of Cdtreated group, the other four Cd-treated groups were significantly $(P<0.05)$ discrete along PC2 axis. At metabolite level, obviously, Cd mainly induced a linear dose-dependent response profile, which accounted for $69.13 \%$ of the variation induced by $\mathrm{Cd}$ in $P$. aibuhitensis. Interestingly, the average PC3 scores for all the six groups (control and five Cd treatments) were shown in a U-shaped curve with the moderate concentration $(80 \mu \mathrm{g} / \mathrm{L})$ of Cd treatment located at the bottom (Fig. $5 \mathrm{C}$ ), which was basically consistent with the profiles from CAT, GST and AChE activities and SOD, HSP 90 and MP expression levels. These findings confirmed the hormesis of $\mathrm{Cd}$ to $P$. aibuhitensis at metabolite level. However, PC3 could only interpret $5.54 \%$ of the variation
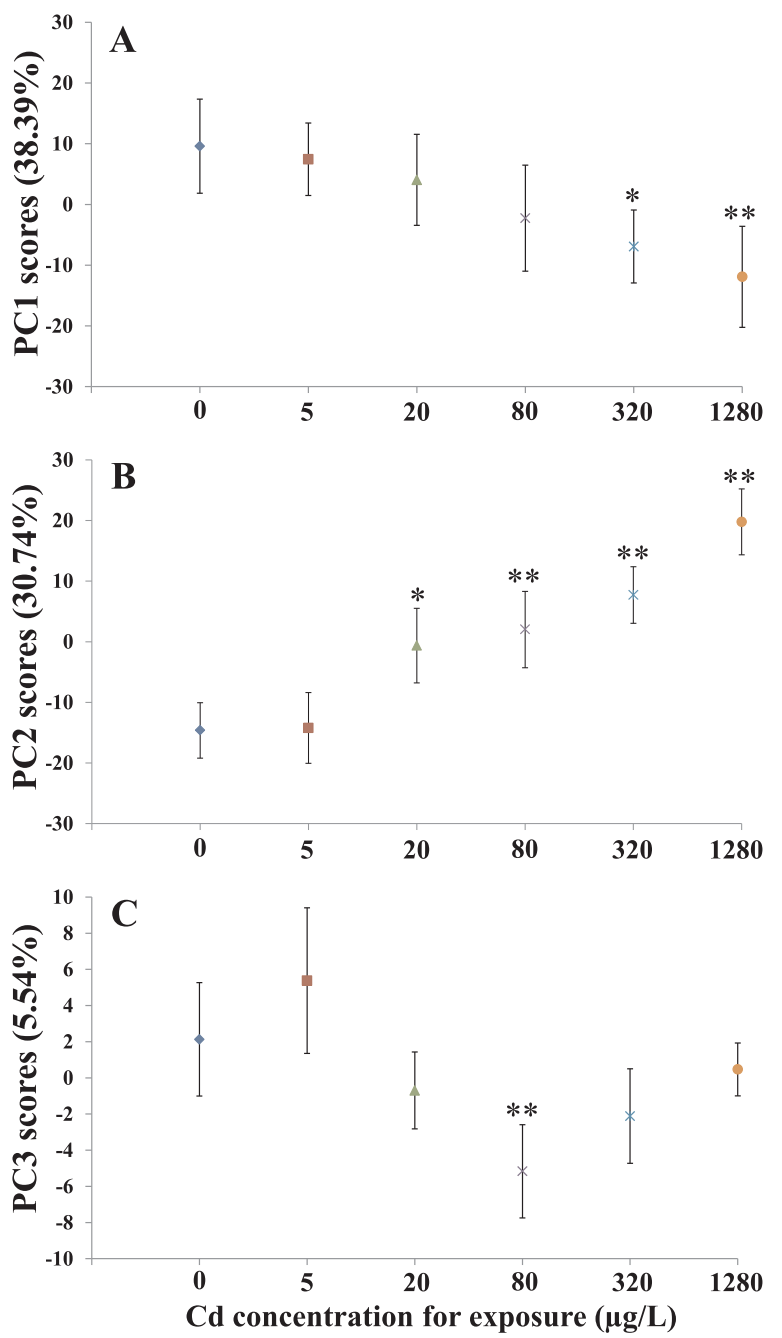

Fig. 5. The average PC scores of control and Cd-treated groups along PC1 (A), PC2 (B) and PC3 (C) axes. PC scores are presented as the mean \pm standard deviation for each group. Statistical significances $(P<0.05$, * and $P<0.01$, $* *)$ between control and Cd treatments were determined by one way ANOVA.

induced by Cd. Therefore, Cd mainly induced linear dose-dependent effects and a relatively slight hormesis in $P$. aibuhitensis at metabolite level.

To characterize the dose-dependent responses to $\mathrm{Cd}$ exposures at metabolite level, all the metabolite concentrations from control and $\mathrm{Cd}$ treatments were quantified using the Chenomx software. One way analysis of variance (ANOVA) with Tukey's test indicated that these metabolites, including branched chain amino acids (BCAAs), saccharopine, glutamine, proline, aspartate, inosine, tyrosine, phenylalanine, acetone, glucose, homarine, AMP and ATP, were significantly altered in Cd-treated groups. The significantly altered metabolites in response to $\mathrm{Cd}$ exposures were summarized in the schematic metabolic pathways (Fig. 6). Basically, most of the responsive metabolites, including leucine, isoleucine, valine, saccharopine, tyrosine, phenylalanine, glucose and aspartate, were shown in linear dose-dependent profiles, which was consistent with the most variation $(69.13 \%)$ interpreted by the linear dose-dependent profiles resulted in both PC1 and PC2 scores, as mentioned above. In marine invertebrates, amino acids are not only involved in energy metabolism, but also used as osmolytes to balance the osmolarity with the saline environment (Preston, 2005; Viant et al., 2003). In this work, the concentrations of amino acids (leucine, isoleucine, valine, tyrosine, phenylalanine and aspartate) were increased with the increased Cd concentrations for exposures. Interestingly, the 


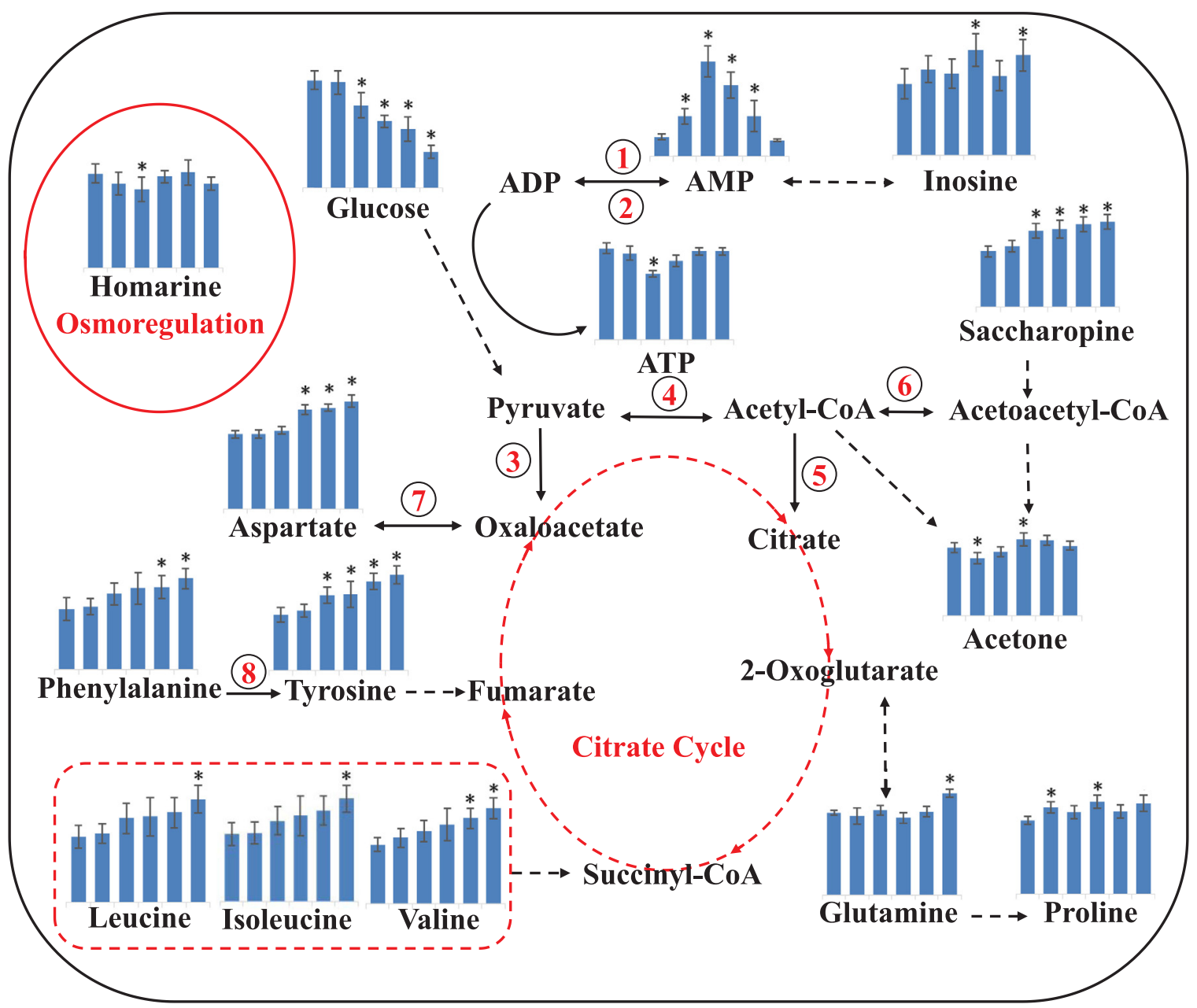

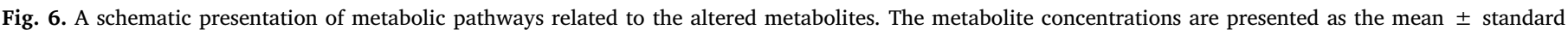

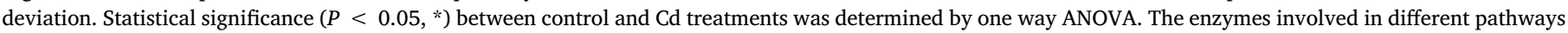

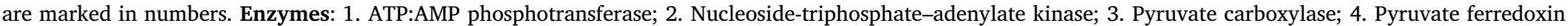
oxidoreductase; 5. Citrate synthase; 6. Acetyl-CoA:acetyl-CoA C-acetyltransferase; 7. Aspartate aminotransferase; 8. Phenylalanine-4-hydroxylase.

concentrations of glucose were decreased with the increased Cd concentrations for exposures. The contents of these amino acids were roughly negatively correlated with the contents of glucose in Cd-treated $P$. aibuhitensis, which suggested that $\mathrm{Cd}$ exposures reduced the consumption of amino acids and enhanced the consumption of glucose for energy supply. Therefore, these altered amino acids were mainly involved in energy metabolism, as shown in the metabolic pathways in Fig. 6. Since saccharopine is an intermediate in the degradation of lysine, it might be also involved in energy metabolism (Pena et al., 2017).

Among these metabolites with significances, ATP and AMP were altered in U-shaped and inverted U-shaped profiles, respectively. Obviously, Cd treatments induced hormesis in the conversion of ATP hydrolysis to AMP. Acetone, a metabolite involved energy metabolism at well, was significantly decreased in the lowest concentration $(5 \mu \mathrm{g} / \mathrm{L})$ of Cd-treated group, while it was significantly increased in the moderate concentration $(80 \mu \mathrm{g} / \mathrm{L})$ of Cd-treated group. This also demonstrated the hormesis of $\mathrm{Cd}$ in $P$. aibuhitensis. However, the Cd concentration range of hormesis was located from 5 to $80 \mu \mathrm{g} / \mathrm{L}$ using acetone as the endpoint. Other metabolites, such as glutamine, proline and inosine, were elevated in some of the Cd treatments without obvious dose-dependent tendencies and probably related to disturbed energy metabolism. As an organic osmolyte, homarine was uniquely decreased in the second lowest concentration $(20 \mu \mathrm{g} / \mathrm{L})$ of Cd-treated group, which suggested the disturbance in the osmoregulation caused by this $\mathrm{Cd}$ exposure. Inosine is a nucleotide that is involved in a chain of purine nucleotides reactions required for muscle movements. It was significantly increased in the moderate $(80 \mu \mathrm{g} / \mathrm{L})$ and highest $(1280 \mu \mathrm{g} /$ L) concentrations of $\mathrm{Cd}$ treatments, suggesting the perturbation in muscle movements induced by these two Cd exposures.

In conclusion, this study revealed the dose-dependent responses induced by $\mathrm{Cd}$ in marine polychaete $P$. aibuhitensis. The endpoints, including activities of enzymes, expression levels of stress-responsive genes and metabolic responses, were characterized to elucidate the dose-dependent responses of $\mathrm{Cd}$ in $P$. aibuhitensis. Both enzyme activities and gene expression levels exhibited the hormetic effects induced by Cd in P. aibuhitensis, resulting in the observable U-shaped or inverted U-shaped response profiles. At metabolite level, however, Cd mainly induced linear dose-dependent effects $(69.13 \%$ of the total variation) and a relatively slight hormesis $(5.54 \%$ of the total variation) in $P$. aibuhitensis. Overall, the moderate $(80 \mu \mathrm{g} / \mathrm{L})$ or the second lowest $(20 \mu \mathrm{g} /$ $\mathrm{L})$ concentration and the highest concentration $(1280 \mu \mathrm{g} / \mathrm{L})$ of $\mathrm{Cd}$ exposures presented typical hormetic responses at enzyme activity, gene expression and metabolite levels. The highest concentration $(1280 \mu \mathrm{g} /$ L) of Cd exposure induced obvious oxidative stress. The metabolic responses suggested that $\mathrm{Cd}$ treatments induced both linear and hormetic effects in energy metabolism. In details, Cd exposures linearly reduced the consumption of amino acids and enhanced the consumption of glucose for energy supply, resulting in elevated contents of amino acids and depleted contents of glucose. Additionally, Cd treatments induced hormesis in the conversion of ATP hydrolysis to AMP. This work 
demonstrated the significant hormetic effects induced by $\mathrm{Cd}$ in $P$. aibuhitensis. Therefore, the hormetic effects should be considered in the ecological risk assessment for the environmental pollutants.

\section{Acknowledgments}

This research was supported by the grants from National Natural Science Foundation of China (41676114), National Key Basic Research Program of China (2015CB453303), Qingdao National Laboratory for Marine Science and Technology (QNLM201701) and the Youth Innovation Promotion Association CAS (2015169).

\section{References}

Bertin, G., Averbeck, D., 2006. Cadmium: cellular effects, modifications of biomolecules, modulation of DNA repair and genotoxic consequences (a review). Biochimie 88, 1549-1559.

Bradford, M., 1976. A rapid and sensitive method for the quantification of microgram quantities of protein utilizing the principle of protein-dye binding. Anal. Biochem. 72, 248-254.

Calabrese, E.J., Baldwin, L.A., 2000. History of chemical hormesis. Hum. Exp. Toxicol. 19, $2-31$.

Calabrese, E.J., Baldwin, L.A., 2003. Hormesis: environmental and biomedical perspectives. Crit. Rev. Toxicol. 33, 213-467.

Chapman, P.M., 2002. Ecological risk assessment (ERA) and hormesis. Sci. Total Environ. 288, 131-140.

De Silva, N.A.L., Marsden, I.D., Gaw, S., Glover, C.N., 2018. Acute waterborne cadmium toxicity in the estuarine pulmonate mud snail, Amphibola crenata. Ecotoxicol. Environ. Saf. 158, 274-283.

Fridovich, I., 1995. Superoxide radical and superoxide dismutases. Annu. Rev. Biochem. 64, 97-112.

Gao, X., Zhou, F., Chen, C.A., 2014. Pollution status of the Bohai Sea: an overview of the environmental quality assessment related trace metals. Environ. Int. 62, 12-30.

Gu, Y.-G., Ning, J.-J., Ke, C.-L., Huan, H.-H., 2018. Bioaccessibility and human health implications of heavy metals in different trophic level marine organisms: a case study of the South China Sea. Ecotoxicol. Environ. Saf. 163, 551-557.

Ji, C., Yu, D., Wang, Q., Li, F., Zhao, J., Wu, H., 2016. Impact of metal pollution on shrimp Crangon affinis by NMR-based metabolomics. Mar. Pollut. Bull. 106, 372-376.

Lewis, S., Handy, R., Cordi, B., Billinghurst, Z., Depledge, M.H., 1999. Stress proteins (HSP's): methods of detection and their use as an environmental biomarker. Ecotoxicology 8, 351-368.

Li, L., Liu, X., You, L., Zhang, L., Zhao, J., Wu, H., 2012. Uptake pathways and subcellular fractionation of $\mathrm{Cd}$ in the polychaete Nereis diversicolor. Ecotoxicology 21, 104-110.

Liang, L., He, B., Jiang, G., Chen, D., Yao, Z., 2004. Evaluation of mollusks as biomonitors to investigate heavy metal contaminations along the Chinese Bohai Sea. Sci. Total Environ. 324, 105-113.

Liu, X., Shen, G., Xu, H., He, L., 2016. The fenpropathrin resistant Tetranychus cinnabarinus showed increased fecundity with high content of vitellogenin and vitellogenin receptor. Pestic. Biochem. Physiol. 134, 31-38.

Livak, K.J., Schmittgen, T.D., 2001. Analysis of relative gene expression data using real- time quantitative PCR and the 2(-Delta Delta C(T)) method. Methods 25, 402-408.

Ma, J., Shao, M., Bao, Y., Yin, J., 1995. Current status and assessment of bays of the Bohai Sea and Huanghai Sea in Liaoning Province. Res. Environ. Sci. 8, 27-34 (In Chinese with English abstract).

Pavlakia, M.D., Morgado, R.G., Van Gestel, C.A.M., Calado, R., Soares, A.M.V.M., Loureiro, S., 2017. Influence of environmental conditions on the toxicokinetics of cadmium in the marine copepod Acartia tonsa. Ecotoxicol. Environ. Saf. 145, $142-149$.

Nascarella, M.A., Stoffolano Jr., J.G., Stanek III, E.J., Kostecki, P.T., Calabrese, E.J., 2003. Hormesis and stage specific toxicity induced by cadmium in an insect model, the queen blowfly, Phormia regina Meig. Environ. Pollut. 124, 257-262.

Pena, I.A., Marques, L.A., Laranjeira, A.B.A., Yunes, J.A., Eberlin, M.N., MacKenzie, A., Arruda, P., 2017. Mouse lysine catabolism to aminoadipate occurs primarily through the saccharopine pathway; implications for pyridoxine dependent epilepsy (PDE). Biochim. Biophys. Acta 1863, 121-128.

Preston, R.L., 2005. Transport of amino acids by marine invertebrates. Comp. Physiol. Biochem. 265, 410-421.

Quinn, D.M., 1987. Acetylcholinesterase: enzyme structure, reaction dynamics, and virtual transition states. Chem. Rev. 87, 955-979.

Srinivasan, S., Avadhani, N.G., 2012. Cytochrome c oxidase dysfunction in oxidative stress. Free Radic. Biol. Med. 53, 1252-1263.

Stebbing, A.R.D., 1998. A theory for growth hormesis. Mutat. Res. 403, 249-258.

Stebbing, A.R.D., 2000. Maia hypothesis - growth control and toxicology. Hum. Ecol. Risk Assess. 6, 301-311.

Tian, Y., Liu, H., Wang, Q., Zhou, H., Tang, X., 2014. Acute and chronic toxic effects of $\mathrm{Pb}^{2+}$ on polychaete Perinereis aibuhitensis: morphological changes and responses of the antioxidant system. J. Environ. Sci. 26, 1681-1688.

Viant, M.R., Rosenblum, E.S., Tjeerdema, R.S., 2003. NMR-based metabolomics: a powerful approach for characterizing the effects of environmental stressors on organism health. Environ. Sci. Technol. 37, 4982-4989.

Viant, M.R., Bearden, D.W., Bundy, J.G., Burton, I.W., Collette, T.W., Ekman, D.R., Ezernieks, V., Karakach, T.K., Lin, C.Y., Rochfort, S., De Ropp, J.S., Teng, Q., Tjeerdema, R.S., Walter, J.A., Wu, H., 2009. International NMR-based environmental metabolomics intercomparison exercise. Environ. Sci. Technol. 43, 219-225.

Xu, L., Ji, C., Zhao, J., Wu, H., 2016. Metabolic responses to metal pollution in shrimp Crangon affinis from the sites along the Laizhou Bay in the Bohai Sea. Mar. Pollut. Bull. 113, 536-541.

Yang, D., Zhou, Y., Chen, X., Zhou, X., Wang, B., Yuan, X., Sun, J., 2011. Cloning and expression of the metalloprotein (MPII) gene from polychaetes Perinereis aibuhitensis (Annelida: Polychaeta). J. Fish. Sci. China 18, 983-991 (In Chinese with English abstract).

Zhang, L., Liu, X., You, L., Zhou, D., Wu, H., Li, L., Zhao, J., Feng, J., Yu, J., 2011. Metabolic responses in gills of Manila clam Ruditapes philippinarum exposed to copper using NMR-based metabolomics. Mar. Environ. Res. 72, 33-39.

Zhang, L.J., Li, Y., Chen, P., Li, X.M., Chen, Y.G., Hang, Y.Y., Gong, W.J., 2017. A study of genotoxicity and oxidative stress induced by mercuric chloride in the marine polychaete Perinereis aibuhitensis. Environ. Toxicol. Pharmarcol. 56, 361-365.

Zhang, X., 2001. Investigation of pollution of $\mathrm{Pb}, \mathrm{Cd}, \mathrm{Hg}$, as in sea water and deposit of Bohai Sea area. Heilongjiang Environ. J. 25, 87-90 (In Chinese with English abstract).

Zhang, Y., Shen, G., Yu, Y., Zhu, H., 2009. The hormetic effect of cadmium on the activity of antioxidant enzymes in the earthworm Eisenia fetida. Environ. Pollut. 157 3064-3068. 